\title{
ANAESTHETIC MANAGEMENT OF A CASE OF HEREDITARY SPHEROCYTOSIS FOR SPLENECTOMY AND CHOLECYSTECTOMY.
}

Jyotsna P. Bhosale, Souvik Paul.
1. Assistant Professor, Department of Anaesthesiology, Bharati Vidyapeeth Deemed University Medical College, Pune.
2. Lecturer, Department of Anaesthesiology, Bharati Vidyapeeth Deemed University Medical College, Pune.

\section{CORRESPONDING AUTHOR}

Dr. Jyotsna P. Bhosale

Aishwarya Residency 1, Flat No. 1, Jagtap Chowk, Wanawadi

Pune -411040,

E-mail: drjyotsnabhosale20@gmail.com, souvikpaul10@gmail.com

Ph: 00919850764826.

ABSTRACT: We report successful anaesthetic management of a patient with hereditary spherocytosis who underwent laproscopic splenectomy, cholecystectomy and appendioectomy. Hereditary spherocytosis is a familial hemolytic disorder with marked heterogeneity of clinical features, ranging from asymptomatic condition to a fulminant hemolytic anaemia. Commonly recommended perioperative management in these patients includes preemptive erythrocyte transfusion, aggressive hydration and avoidance of hypoxia, aplastic crisis, hypothermia and acidosis. The management of such a case is challenging from anaesthetic point of view because of sickling oriented anaesthetic approach. Key words: Hereditary spherocytosis, splenectomy, cholecystectomy, perioperative management.

KEY WORDS: Hereditary spherocytosis, splenectomy, cholecystectomy, perioperative management.

INTRODUCTION: Hereditary spherocytosis is a genetically transmitted (autosomal dominant) form of spherocytosis. It is an auto-hemolytic anemia characterized by the production of red blood cells that are sphere-shaped rather than biconcave disc shaped and therefore more prone to hemolysis.1,2,3 An osmotic fragility test can aid in the diagnosis.2

It is characterized by anaemia jaundice and splenomegaly.1,2,3,4 The perioperative management of a patient with hereditary spherocytosis is challenging because of sickling oriented anaesthetic approach. The key to successful management of a such a patient is to avoid triggering factors, vigilant perioperative monitoring and aggressive treatment of aplastic crisis hypothermia, hypotension.

CASE REPORT: A 32 year old female presented with right upper quadrant pain and nausea. On physical examination she had pallor, icteric sclera and splenomegaly. She had past history of jaundice 9 years back for which she had received conservative management. Also patient had history of icteric sclera since childhood. Though her past medical history was typical of hereditary spherocytosis, she was diagnosed as a case of hereditary spherocytosis only on admission on basis of her history and investigations.

Her preoperative investigations were as follows: USG abdomen and pelvis was suggestive of appendicitis, splenomegaly and cholelithiasis, $\mathrm{Hb}: 6.2 \mathrm{gm} \%$, reticulocyte count: 18.5\%, PBS : Hereditary spherocytes (+), osmotic fragility $\uparrow$ ed, Coomb’s test was negative.

Journal of Evolution of Medical and Dental Sciences/Volume1/Issue5/November-2012Page-784 
In the liver function tests, total serum bilirubin was $5.8 \mathrm{mg} / \mathrm{dl}$ and indirect bilirubin was 5.4 $\mathrm{mg} / \mathrm{dl}$ and PT/INR was 27/2 (Control $13.5 \mathrm{sec}$ ). Platelet count was 1 lakh / mm3. Investigations were within normal limits.

Patient received five units of packed cell volume, five units fresh frozen plasma and inj Vit K $30 \mathrm{mg}$ iv preoperatively. Her post-transfusion invest were as follows.

$\mathrm{Hb}$ : 9.9 gm\%, platelet count: 71,000/mm3 and PT/INR:18.1/1.35. Before surgery, she was given vaccine against pneumococci, $\mathrm{H}$-influenza and hepatitis $\mathrm{B}$.

Considering preoperative investigations and the need of the surgery, it was decided to proceed with general anaesthesia. Preoperatively 3 units fresh frozen plasma, 2 units platelet concentrates and 2 units packed cell volume were keep ready.

In the operation theatre intravenous line was secured with $18 \mathrm{G}$ intracath. The patient was premedicated with intravenous glycopyrrolate $0.2 \mathrm{mg}$. Monitoring included ECG pulse oximetry, NIBP and EtCO2, temperature and urine output. Pre-induction patient was given inj midazolam $0.5 \mathrm{mg}$ and fentanyl $50 \mu \mathrm{g}$. After adequate preoxygenation patient was induced with i.v Inj. Thiopentone sodium $5 \mathrm{mg} / \mathrm{kg}$ and muscle relaxation was achieved with succinylcholine 2 $\mathrm{mg} / \mathrm{kg}$. Intubation was done gently with 6.5 no cuffed portex tube. Anaesthesia was maintained with 50\% N20 in 02 and isoflurane $(0.2-1 \%)$ and intermittent top-ups of vecuronium.

Intra-operatively patient received 3 units fresh frozen plasma, 2 units platelet concentrates. Patient was given 1 unit packed cell volume after clamping splenic vessels. Intraop hypothermia was avoided using warm IV fluids, properly covering the patient and monitoring temperature.

Intra-operative hypoxia was prevented by providing $50 \%$ Fi 02, giving IPPV, monitoring SP02. Hypoperfusion was prevented maintaining adequate intra vascular volume with crystalloids, FFP, platelet concentrates and PCV and hypotension was prevented by giving titrated dose of isoflurane and fentanyl and maintaining adequate intravascular volume.

Intraoperatively the patient was stable. The duration of surgery was 7 hours. At the end of surgery, the neuromuscular block was reversed with Inj. neostigmine $2.5 \mathrm{mg}$ and Inj glycopyrrolate $0.4 \mathrm{mg}$. Patient was extubated and shifted to ICU for monitoring.

DISCUSSION: Hereditary spherocytosis is a rare inherited red cell membrane disorder that is characterized by spherically shaped red blood corpuscles on peripheral blood smear.2,3,4 It was described in initially in 1871.5 Spherocytosis results from red cell membrane defect.4 Spectin deficiency is the most common defect. Complications of hereditary spherocytosis include gallstones, aplastic, hemolytic and megaloblastic crises, poor growth and skeletal deformities.2,3,4

For practical purpose, the treatment of hereditary spherocytosis involves splenectomy, pre and post splenectomy care. Commonly recommended perioperative management includes preemptive erythrocyte transfusion, aggressive hydration, avoidance of hypoxia, hypothermia and acidosis.6,7

Anaesthesia management of patient of hereditary spherocytosis is challenging. Avoidance of hypoxaemia is the key goal. Premedication and opioid based analgesia has to be used with extreme caution because of concern about respiratory depression, hypoxia and sickling.8 Intraop hypothermia is to be avoided to minimize vasoconstriction and associated circulatory stasis.

Splenectomy is very effective in reducing hemolysis leading to significant prolongation of red cell span. The clinical manifestations and complications (anaemia and gallstones) are 
much reduced in hereditary spherocytosis but at the price of life threatening sepsis from encapsulated organism particularly streptococcus pneumonia.9

For pre-splenectomy vaccination and post-splenectomy follow up, our patient was preoperatively vaccinated and also advised to repeat pneumococcal vaccination at 5 year intervals.

CONCLUSION: The patient of hereditary spherocytosis is at increased risk for developing various complications like aplastic or megaloblastic crisis, hemolytic crisis, acute chest syndrome stroke, etc. The anaesthetist should have better understanding of silent but insidious end-organ damage (brain, kidney and lungs). This allows for more accurate preoperative assessment. It also points to the development of potentially effective ways to avoid and treat complications.

\section{REFERENCES:}

1. The Lancet, volume 372, Issue 9647, 1411-26, 18 Oct. 2008.

2. Hoffbrand AV, Petit JE, Moss PAH. Hereditary hemolytic anaemias. In: Essential haemotology. 4th Ed. Massachusetts Blackwell science, 2001:60-63.

3. Gallager PG, Forget BG. Hereditary spherocytosis, elliptocytosis and related disorders. In: Williams Haemotology, 6th Ed. Chicago : McGraw Hill, 2000: 1189-1209.

4. Pallister C. Disorders of red cell survival. In: Blood Physiology and pathophysiology. Oxford : Butterworth-Heinemann, 1994: 33-52.

5. Shafqat S, Roger V, Hereditary Spherocytosis. Paediatrics in Review 2004; 25:168-172.

6. Steinberg MH. Management of sickle cell disease N Eng J. Med 1999; 340:1021-30.

7. Vichinsky EP, Haberkern CM, Neumary L, et al. A comparision of conservative and aggressive transfusion regimens in the perioperative management of sickle cell disease. The preoperative transfusion in Sickle Cell Disease Study Group. N Eng J. Med 1995; 333:206-13.

8. Shapiro ND, Poe MF. Sickle Cell disease; an anaesthesiological problem, Anaesthesiology 1995; 16:771-80.

9. P. H. B. Bolton - Maggs, R. F. Stevens et al. Guidelines for diagnosis and management of hereditary spherocytosis, British Journal of Haemotology, 2004;126, 455-74. 